\title{
Outcome measures in early psychosis
}

\author{
Relevance of duration of untreated psychosis
}

SWARAN P. SINGH

\author{
Background Duration of untreated \\ psychosis (DUP) is considered an \\ important predictor of short-term clinical \\ outcome.
}

\begin{abstract}
Aims To explore the evolution of the concept of DUP, synthesise the evidence for its predictive value, highlight the problems in measurement, and consider the potential pitfalls of using DUP as a measure of the effectiveness of early intervention services.
\end{abstract}

Method A survey of recent literature was conducted.

Results Several studies and two systematic reviews conf irm that DUP has a robust but moderate effect on outcome in schizophrenia. Studies vary widely in how DUP is defined and measured, since identifying precise time points when psychosis emerges and remits is conceptually ambiguous and clinically difficult.

Conclusions Standardised measurement of DUP is a vital first step in allowing comparisons between studies. Duration of untreated psychosis is a relevant measure only of the early detection function of early intervention services.

Declaration of interest S.S. has received honoraria and educational grants from several pharmaceutical companies.
In the past two decades, the duration of untreated psychosis (DUP) has been an intense focus of clinical and research interest, with the recognition that not only is long DUP associated with poor outcome, but that as a potentially malleable prognostic factor, reducing it at a population level might have a significant public health impact. The suggestion that untreated psychosis may itself be toxic, contributing to a neurodegenerative process, also opens up the possibility of better understanding of the pathophysiology of schizophrenia and the impact of treatment in ameliorating such pathology (McGlashan, 2006). Several studies and two systematic reviews have demonstrated that DUP is an independent predictor of the likelihood and magnitude of recovery in first-episode schizophrenia, although with a small-to-moderate effect (Marshall et al, 2005; Perkins et al, 2005). This paper will explore the historical evolution of the concept of DUP, summarise the evidence on whether DUP is a marker or a determinant of the course of schizophrenia, identify the potential clinical and research problems in defining and measuring DUP, and consider whether DUP is appropriate as a measure of the effectiveness of early intervention services.

By the mid 1980s, studies had begun to demonstrate the importance of the time period between the onset of psychosis and initiation of treatment in determining outcome in schizophrenia (Johnstone et al, 1986; Rabiner et al, 1986). The Northwick Park Study of first-episode schizophrenia found that the most important determinant of relapse was duration of illness prior to starting antipsychotics (Johnstone et al, 1986). 'Length of manifest illness' came to be seen as an important contributor to the heterogeneity of outcome in schizophrenia (McGlashan, 1988). It was Wyatt's seminal review of antipsychotics and the natural course of schizophrenia that firmly established the importance of the length of untreated psychosis as a prognostic indicator
(Wyatt, 1991). Wyatt also speculated that untreated psychosis might itself be biologically toxic. Length of untreated psychosis/ manifest illness merged into the construct of DUP, and the importance of measuring it developed alongside the first-episode services and research programmes burgeoning across several continents.

\section{DOES DUP DETERMINE OUTCOME?}

If 'untreated' in DUP refers to pharmacological treatment then, before the introduction of antipsychotics in the 1960s, DUP was the length of the psychotic illness itself. Moreover, if progressive deterioration in untreated patients were inevitable, there would have been an evident improvement in the outcome of psychosis after the introduction of antipsychotics. Recovery rates did increase in the mid-20th century but antipsychotics have not made a huge difference to the proportion of patients in remission in long-term follow-up studies (Hegarty et al, 1994). So does DUP matter?

Besides the humane reasons for reducing DUP and ameliorating unnecessary suffering, there does appear to be a robust, if moderate, effect of long DUP on poor outcome in schizophrenia. In a systematic review of 26 first-episode studies, Marshall et al (2005) found that although a longer DUP was not associated with worse symptoms or poorer functioning at first presentation, at 6 and 12 months following treatment longer DUP was associated with more severe overall symptoms and with worse overall functioning. People with longer DUP were also less likely to experience remission at 6,12 and 24 months. In a similar review of 43 publications, but using a different meta-analytical strategy, Perkins et al (2005) found that at first presentation longer DUP was associated with more severe negative but not positive symptoms or neurocognitive functioning, and with lower levels of symptomatic and functional recovery from the first episode. Shorter DUP was thus associated not only with greater 'treatment responsiveness' but also with greater reduction in negative symptoms, an interesting finding given that negative symptoms are considered less responsive to antipsychotics than positive symptoms. A recent study has even attempted to enumerate the precise effect of DUP on outcome, reporting that each unit increase in DUP is associated with a 
7.8-point increase in global functioning scores and a 1.9-point increase in positive symptom scores (Clarke et al, 2006).

\section{HOW LONG IS A LONG DUP?}

The relationship between long DUP and poor outcome is not linear: very long DUP does not correlate with extremely poor outcome. Deterioration in schizophrenia is also unlike that in Huntington's chorea or Alzheimer's disease in that it does not go 'all the way' but rather reaches a plateau after a few years (McGlashan, 2006). A study of untreated patients from Chennai, South India (Tirupati et al, 2004) found that treatment response is evident even in patients with a DUP of longer than 15 years. In this study, a DUP of less than 5 years predicted good clinical but not occupational outcome, although occupational outcome in such regions is influenced by the family and societal response to the illness rather than being a core feature of the disability itself. So can DUP be meaningfully dichotomised to predict good $v$. poor outcome?

So far, no demonstrable relationship has been confirmed between effect size of DUP on outcome and the cut-off point chosen to define long or short DUP. Different studies have identified different cut-offs. One study suggested that intensive treatment enhances outcome only if the DUP is less than 6 months (Carbone et al, 1999) whereas another reported that outcomes were significantly worse when DUP exceeded 3 months (Harris et al, 2005). Functional outcome appears to decline substantially even after very short treatment delays ( $>7$ days), with more gradual deterioration in functioning up to a very long DUP (>1 year; Harrigan et al, 2003). There does not appear to be a cut-off point associated with medium- to long-term impairment, with some domains of outcome more sensitive to treatment delay than others.

Marshall et al (2005) have suggested that the cut-off must be very close to onset of psychosis to demonstrate a dichotomous effect. However, the application of a very short cut-off leads to confounding between DUP, outcome and diagnosis (such as acute and transient psychotic disorders). McGlashan (2006) has postulated 'a window of deterioration' in the late prodromal phase when neurcognitive decline in particular occurs. Findings that brain abnormalities pre-date frank expression of psychosis make a strong case for intervention in the prodrome of psychosis (Zipursky et al, 1998; Pantelis et al, 2003). However, we are no clearer as to the 'critical period' of DUP, exceeding which inevitably predicts poor outcome.

\section{IS DUP CONFOUNDED?}

Does the treatment of psychosis treat symptoms alone or the underlying neuropathological processes? In the latter case, the association between DUP and outcome is easy to understand. In the alternative analysis, shorter DUP is a reflection of prognosis. In this concept DUP is confounded by personality and/or illness-related variables, with a combination of insidious onset, negative symptoms and premorbid dysfunction contributing to delayed help-seeking, delayed initiation of treatment and poorer outcome. Long DUP and later treatment are thus a consequence rather than a cause of other indicators of poor prognosis (Barnes et al, 2000; Verdoux et al, 2001). These confounding prognostic indicators include among others age at onset, gender, premorbid functioning, socio-economic status and mode of onset (Norman et al, 2001; Perkins et al, 2005). Moller (2000) found that a later prodrome onset (mean age in their sample 20.5 years), a prodrome shorter than 2 years, acute initial development of psychosis, the initial presence of grandiosity and/or disorganisation, and a mild level of withdrawal all reduce treatment delay. Mode of onset and premorbid functioning therefore represent built-in components of psychotic illnesses related to a shortened DUP, irrespective of efforts at early intervention.

There is evidence that, even after adjusting for the effects of such confounders, DUP is a significant predictor of outcome. Acute onset, although associated with a shorter duration of initial episode, is not an independent predictor of outcome in psychosis when gender and premorbid functioning are controlled (Singh et al, 2004). Loebel et al (1992) reported that whereas good premorbid functioning is related to higher levels of remission but not a shorter time to remission, shorter DUP correlates with both, suggesting that DUP is a stronger prognostic indicator, perhaps being independent of premorbid functioning. Several other studies that have controlled for premorbid functioning or mode of onset have consistently found that DUP is an independent predictor of outcome (Verdoux et al, 2001; Harrigan et al, 2003; Addington et al, 2004; Melle et al, 2004). Marshall et al (2005) concluded that, although DUP and outcome may be confounded by some third variable, at least in their meta-analysis, premorbid adjustment was not that third variable.

\section{CAN DUP BE RELIABLY MEASURED?}

In their extensive review Norman \& Malla (2001) identified several conceptual and methodological problems in how DUP is defined and measured. These include problems in establishing and dating the onset of psychosis, the onset of treatment and the adequacy of treatment.

\section{When does DUP begin?}

Onset of psychosis is a nebulous phenomenon that evades close scrutiny. Establishing onset has become increasingly important for early identification and intervention in psychosis. Yet there is no consensus definition of onset of psychosis and the literature yields few standardised replicable methods for measuring onset (Singh et al, 2005a). Researchers have often reverted to a single global measure of onset based upon clinical judgement. It is not always made clear whether onset refers to the onset of illness or the onset of psychosis. Where emergence of psychotic symptoms is considered the unequivocal onset of psychosis, there are still problems of patient $v$. observer rating of onset and recall bias in retrospective assessments. Clinically it is difficult to identify a precise time when a certain behaviour or symptom makes the transition from a non-psychotic to a psychotic domain, with considerable arbitrariness introduced in both identifying and dating the phenomenon. There is often a phenomenological, temporal and experiential continuity between pre-psychotic and psychotic symptoms (Moller, 2001). Definitions of onset thus vary from the interval between first sign of illness and the appearance of florid psychotic symptoms (Vaillant, 1964) to the interval between appearance of psychotic symptoms to the initiation of treatment (Day et al, 1987).

Yung and colleagues set up the Personal Assessment and Crisis Evaluation (PACE) clinic in Melbourne, Australia, in the 1990s to prospectively monitor and provide care 
for young people considered 'at risk' of impending psychosis. In a series of papers, they have described and refined the concept of 'at-risk states' (Yung \& McGorry, 1996; Yung et al, 1998; Phillips et al, 2000). The at-risk states include a combination of familial risk (positive family history of psychosis), recent-onset drop in functioning, attenuated or sub-threshold symptoms and brief limited intermittent psychotic symptoms (BLIPS). Attenuated symptoms differ from frank psychotic symptoms in their intensity, frequency and/or duration. Brief limited intermittent psychotic symptoms are frank psychotic symptoms (delusions, hallucinations or thought disorder) which are unequivocally present but last for less than 1 week, resolving spontaneously. Between 30 and $40 \%$ of people presenting with such at-risk states make a transition to psychosis, usually within 6 months. A structured instrument is now available, the Comprehensive Assessment of At-Risk Mental States (CAARMS; Yung et al, 2005), which identifies a group at ultra-high risk of making a transition to psychosis. The use of such measures in the general population is problematic since the positive predictive value becomes extremely low in that setting (Warner, 2002). In addition the positive prediction of psychosis appears to be falling in the new prodromal services that are being established (Riecher-Roessler, 2006). This may partly be because such services detect at-risk individuals even earlier (longer duration of prodrome), when emergence of psychosis is more distant in the future and symptoms are even more non-specific.

The PACE clinic is a well-developed and established service that can provide care for large enough numbers of people to allow prospective studies in an at-risk group. However, in most early intervention programmes patients enter the study/treatment after the development of psychosis and DUP can only be measured retrospectively. Several conceptual and methodological problems hinder the measurement of DUP retrospectively. Should onset of psychosis be the onset of any BLIP or the onset of psychotic symptoms that last more than 1 week? Is it possible to make a retrospective judgement of when a sub-threshold symptom crosses the threshold? Can people precisely recall the severity and duration of symptoms that first appeared some months/ years ago? What about individuals who report quasi-psychotic symptoms even in childhood, with no identifiable time point where schizotypal traits make a transition to a psychotic state (Poulton et al, 2000)?

\section{When does DUP end?}

The end of the period of untreated psychosis is conceptually simpler to date, but 'the start of treatment' is in reality a similarly complex construct. Does 'untreated psychosis' end when any treatment begins, when antipsychotics are started, when antipsychotic treatment at an adequate dose has been adhered to for an adequate period, or when psychosis itself remits? Many studies do not make these distinctions clear in their measure of DUP and scales often do not include a precise definition of treatment adequacy. In routine practice, clinicians sometimes initiate antipsychotics in the prodromal stages of psychosis (Singh et al, 2005a). How should DUP be measured in such cases? In psychosis with prominent mood symptoms at onset, should treatment with antidepressants or mood stabilisers without antipsychotics be considered treatment and hence the end of the period of untreated psychosis? However, what about non-pharmacological treatments which may or may not have an impact on the transition into psychosis (Morrison et al, 2006)?

\section{Structured DUP assessment scales}

Some scales have been developed to retrospectively map the onset of psychosis. Beiser et al (1993) derived a checklist of behaviours describing the evolution of first noticeable symptoms, emergence of psychosis and initiation of treatment-seeking. The Interview for the Retrospective Assessment of the Onset of Schizophrenia (IRAOS; Hafner et al, 1992) is a semi-structured interview to assess symptoms, psychological impairment and socio-demographic characteristics in the time course of emerging psychosis. The Nottingham Onset Schedule (Singh et al, 2005a) is a short, guided interview and rating schedule to measure onset in psychosis. Onset in the Nottingham Onset Schedule is defined as the time between the first reported/observed change in mental state/behaviour and the development of psychotic symptoms. Onset is conceptualised as comprising: (a) a prodrome of two parts (a period of 'unease' followed by 'non-diagnostic' symptoms); (b) appearance of psychotic symptoms; and (c) a build-up of diagnostic symptoms leading to a definite diagnosis. The Nottingham Onset Schedule provides a standardised and reliable means of recording early changes in psychosis and identifying relatively precise time points for measuring several durations in emerging psychosis. By varying the starting point of onset, it also allows for several ways of defining and measuring treatment delays, including duration of untreated illness (from start of prodrome to treatment), duration of untreated emergent psychosis (from first psychotic symptom to treatment) and duration of untreated manifest psychosis (from appearance of fully developed psychotic syndrome to treatment).

Table 1 shows a selected number of studies, chosen to demonstrate differences in how the start and end of the period of untreated psychosis are defined and its length ascertained. Given the problems of measuring DUP, it would be surprising if a degree of enforced 'spurious precision' did not creep into its measurement. Marshall et al (2005) found that only 12 out of 26 studies included in their review reported a systematic method to assess DUP, with only 5 using a structured instrument (IRAOS in 4, the Royal Park Multidiagnostic Instrument for Psychosis in 1) (Marshall et al, 2005). Overall mean DUP in their meta-analysis was 124 weeks (or 103 weeks excluding an outlier with mean DUP of 796 weeks).

\section{IS DUP A VALID MEASURE OF EFFECTIVENESS OF EARLY INTERVENTION SERVICES?}

In the UK, the Department of Health has set a national early intervention target of reducing DUP to a service median of 3 months and an individual maximum of 6 months (National Institute for Mental Health in England, 2006). Notwithstanding the methodological problems in measuring DUP, there is the much larger question of whether DUP is an appropriate measure of the effectiveness of early intervention services.

How early is early intervention? It can mean improving outcomes in people with established psychosis by facilitating and consolidating recovery, detecting hidden morbidity in the community by identifying untreated cases of the disorder, or preventing the emergence of psychosis through prepsychotic interventions. These are different aims, requiring different service models and strategies, and having differing weights of evidence supporting their use (Singh \& Fisher, 2000). 
Table I Selected studies showing variations in definition and measurement of duration of untreated psychosis

\begin{tabular}{|c|c|c|c|c|}
\hline \multirow[t]{2}{*}{ Study } & \multicolumn{2}{|c|}{ Definition } & \multirow{2}{*}{$\begin{array}{l}\text { Structured } \\
\text { assessment }\end{array}$} & \multirow{2}{*}{$\begin{array}{l}\text { DUP, weeks: } \\
\text { mean (median) }\end{array}$} \\
\hline & Start of DUP & End of DUP & & \\
\hline Addington et al (2004) & $\begin{array}{l}\text { First appearance of a positive symptom rated } \\
\geqslant 4 \text { on the PANSS that lasted throughout the } \\
\text { day for several days or several times a week }\end{array}$ & Onset of first effective treatment & IRAOS & $84.2(28)$ \\
\hline Browne et al (2000) & $\begin{array}{l}\text { Time of emergence of psychotic symptoms as } \\
\text { dated by patient on basis of SCID interview }\end{array}$ & Initiation of treatment & No & $90.8(26)$ \\
\hline Carbone et al (1999) & Time of onset of first psychotic symptoms & $\begin{array}{l}\text { Entry into treatment programme that includes } \\
\text { administration of antipsychotic medication }\end{array}$ & RPMIP & $\begin{array}{l}\text { EPPIC } \\
25.0(7.4) \\
\text { Pre-EPPIC } \\
32.4(4.3)\end{array}$ \\
\hline Haas et al (1998) & $\begin{array}{l}\text { A review of all available sources (interviews } \\
\text { with patients, family members, treating clinicians } \\
\text { and medical records) were used by two senior } \\
\text { clinicians in order to provide a best estimate of } \\
\text { time of onset of first psychotic episode }\end{array}$ & First antipsychotic medication & No & 74.4 \\
\hline Häfner et al (1993) & $\begin{array}{l}\text { Onset of first-rank symptoms or meeting criteria } \\
\text { for a syndrome based on patient interview }\end{array}$ & Hospitalisation & IRAOS & $109.2^{1}$ \\
\hline Ho et al (2000) & $\begin{array}{l}\text { Occurrence of delusions, hallucinations, bizarre/ } \\
\text { disorganised behaviours, formal thought disorder, } \\
\text { or catatonic behaviour at moderate or greater } \\
\text { severity }\end{array}$ & Initiation of antipsychotic treatment & $\mathrm{CASH}$ & $60.8(13.5)$ \\
\hline Larsen et al (1996) & $\begin{array}{l}\text { Score of } \geqslant 4 \text { on PANSS positive sub-scale or } \\
\text { inappropriate or bizarre behaviour for several } \\
\text { weeks }\end{array}$ & $\begin{array}{l}\text { Hospitalisation for psychosis or initiation of } \\
\text { antipsychotics for sufficient time and dosage } \\
\text { that would lead to clinical response in average } \\
\text { patient with non-chronic illness (e.g. haloperidol } \\
5 \mathrm{mg} / \text { day for } 3 \text { weeks) }\end{array}$ & No & $114.2(26)$ \\
\hline Malla et al (2002) & $\begin{array}{l}\text { Onset of first psychotic symptoms contiguous } \\
\text { with presenting episode }\end{array}$ & $\begin{array}{l}\text { Having received antipsychotic therapy for of } \\
2 \text { months unless significant response to } \\
\text { medication was achieved earlier }\end{array}$ & No & 44.6 \\
\hline Perkins et al (2004) & $\begin{array}{l}\text { First psychotic symptom determined by clinical } \\
\text { interview of patient and family }\end{array}$ & Clinically meaningful antipsychotic trial & sOS & 2 \\
\hline Scully et al $(1997)^{3}$ & Age at first admission to a psychiatric hospital & Age at first prescription of antipsychotics & No & 722.8 \\
\hline Singh et al (2005b) & Onset of psychotic symptoms & $\begin{array}{l}\text { Commencement of antipsychotics with } \\
\text { adherence (at least } 75 \% \text { of prescribed dose } \\
\text { taken for at least } 75 \% \text { of the time) }\end{array}$ & NOS & $25.5(7.4)$ \\
\hline Szymanski et al (1996) & $\begin{array}{l}\text { The first time at which psychotic symptoms } \\
\text { were noticed by the patient, family or others } \\
\text { in the context of a decline in functioning }\end{array}$ & $\begin{array}{l}\text { Entry into research study involving } \\
\text { administration of antipsychotics based on } \\
\text { clinical judgement of treating physician }\end{array}$ & No & 166.4 \\
\hline Wiersma et al (1998) & $\begin{array}{l}\text { Estimates of psychosis onset were based on } \\
\text { WHO structured instruments }\end{array}$ & $\begin{array}{l}\text { Initiation of any form of treatment (almost } \\
\text { always involving medication) }\end{array}$ & $\begin{array}{l}\text { Life Chart } \\
\text { Schedule and } \\
\text { WHO Past and } \\
\text { Follow-up } \\
\text { History }\end{array}$ & NA \\
\hline
\end{tabular}

DUP, duration of untreated psychosis; PANSS, Positive and Negative Syndrome Scale; IRAOS, Interview for the Retrospective Assessment of the Onset of Schizophrenia; SCID, Structured Clinical Interview for DSM-IV; RPMIP, Royal Park Multidiagnostic Instrument for Psychosis; EPPIC, Early Psychosis Prevention and Intervention Centre; CASH, Comprehensive Assessment of Symptoms and History; SOS, Symptom Onset in Schizophrenia; NOS, Nottingham Onset Schedule; WHO, World Health Organization.

I. As reported by Larsen et al (1996)

2. Interquartile range $2-24$ months.

3. Long-stay patients with some admitted before the antipsychotics era. 
The Lambeth Early Onset (LEO; Craig et al, 2004) and OPUS (Petersen et al, 2005) trials provide convincing evidence that specialised early intervention teams are more effective than standard care in improving clinical outcomes, satisfaction and treatment adherence. Two relatively recent studies provide some justification for prodromal interventions. A randomised controlled trial in a high-risk prodromal population found that a combination of risperidone and psychotherapy reduced the risk of transition to psychosis (McGorry et al, 2002). Pantelis et al (2003) found that specific brain changes accompany prodromal decline and predate the emergence of frank psychosis. If replicated, such studies will provide compelling justification for intervening in the prodromal phase and if all those in the prodromal phase can be identified and adequately treated, there might be no DUP left to measure.

For now at least, the task of reducing DUP at the community level falls on early detection services, which seek undetected cases of established psychosis rather than those at risk. Such programmes usually involve improving knowledge of psychosis within the community and facilitating access to specialist early intervention services. Conducting a randomised trial of early $v$. late detection is unethical. Hence quasi-experimental designs have been employed to evaluate whether early detection can reduce DUP and improve outcomes while the nature of treatment remains unchanged (Malla et al, 2005). The TIPS project in Norway and Denmark attempted this by comparing outcomes in people with first-episode psychosis who were recruited via an early detection team, with those accessing treatment in an area without early detection but with similar healthcare otherwise. Although the early detection programme did not appear to identify and recruit a large number of previously undetected patients, those entering through this route had shorter DUP (median $5 v .16$ weeks) and better clinical outcomes at 3 months (Melle et al, 2004; Friis et al, 2005; Johannessen et al, 2005). However a 'before and after' comparison following the establishment of an early detection programme in London, Ontario, did not find any reduction in DUP in patients recruited following the early detection initiative (median DUP 24.3 v. 21.9 weeks; Malla et al, 2005). Surprisingly patients recruited after the introduction of the early detection programme were more severally ill and had a longer prodromal period.

So far, therefore, the evidence for the effectiveness of early detection programmes in reducing DUP appears limited. Malla $e t$ al (2005) have argued that increasing general practitioner knowledge of psychosis and increasing their relative 'comfort' in prescribing novel antipsychotics leads to people with milder illness being treated at primary care level, and hence an underestimation of the effect of early detection on DUP. Neither the Scandinavian nor the Canadian study confirmed the presence of a large pool of people with undetected psychosis in the community. This further confirms that DUP is skewed by a small group of outliers with extremely long DUP. Median DUP in well-established community services appears to be relatively low: 52 days for schizophrenia in Nottingham, UK, in one study (Singh et al, $2005 a$ ). Although there may be a case for developing targeted early detection programmes for the small proportion of people with undetected psychosis in the community, the evidence for establishing early detection services is not overwhelming.

\section{CONCLUSIONS}

Long DUP is clearly associated with poor outcome, independent of the confounders so far explored. Early intervention of specialist services in first-episode psychosis does improve outcomes in the short to medium term. Prodromal services, although potentially very exciting and innovative in creating avenues for treating people who seek help and are at high risk of developing a serious mental illness, are not focused on reducing DUP but on preventing transition to psychosis. Given that we are not able to change prognostic factors such as gender, family history and age at onset, DUP is a malleable variable which should and perhaps can be reduced. However, two caveats remain. First, to make studies comparable a consensus, reliable and replicable measure of DUP should be used across studies to reduce the variation introduced by the measurement process; DUP is a complex enough construct anyway. Second, DUP is not a valid measure for establishing the effectiveness of early intervention services that aim solely to provide evidence-based care in an assertive manner without an early detection arm. Most early intervention services do not conduct early detection, and their effectiveness and rationale should be judged on different criteria: those of meeting a clinical need early, comprehensively and with the best possible available combination of psychosocial and biomedical interventions, rather than simply the reduction of DUP.

\section{REFERENCES}

Addington, J., Van Mastrigt, S. \& Addington, D. (2004) Duration of untreated psychosis: impact on 2year outcome. Psychological Medicine, 34, 277-284.

Barnes, T. R. E., Hutton, S. B. Chapman, M. J., et al

(2000) West London first-episode study of schizophrenia. Clinical correlates of duration of untreated psychosis. British Journal of Psychiatry, 177 , 207-2II.

Beiser, M., Erickson, D., Fleming, J. A., et al (1993)

Establishing the onset of psychotic illness. American journal of Psychiatry, I50 1349-1354.

Browne, S., Clarke, M., Gervin, M., et al (2000)

Determinants of quality of life at first presentation with schizophrenia. British Journal of Psychiatry, 176, 173-176.

Carbone, S., Harrigan, S., McGorry, P. D., et al (1999) Duration of untreated psychosis and I2-month outcome in first-episode psychosis: the impact of treatment approach. Acta Psychiatrica Scandinavica, 100, 96-104

Clarke, M., Whitty, P., Browne, S., et al (2006) Untreated illness and outcome of psychosis. British journal of Psychiatry, 189, 235-240.

Craig, T. K., Garety, P., Power, P., et al (2004) The Lambeth Early Onset (LEO) Team: randomised controlled trial of the effectiveness of specialised care for early psychosis. BM/, 329, 1067.

Day, R., Nielsen, J. A., Korten, A., et al (1987) Stressful life events preceding the acute onset of schizophrenia: a cross-national study from the World Health Organization. Culture, Medicine and Psychiatry, II 123-205

Friis, S., Vaglum, P., Haahr, U., et al (2005) Effect of an early detection programme on duration of untreated psychosis. Part of the ScandinavianTIPS study. British Journal of Psychiatry, 187 (suppl. 48), s29-s32.

Haas, G. L., Garratt, L. S. \& Sweeney, J. A. (1998) Delay to first antipsychotic medication in schizophrenia: impact on symptomatology and clinical course of illness. Journal of Psychiatric Research, 32, 151-159.

Hafner, H., Riecher-Rossler, A., Hambrecht, M., et al (1992) IRAOS: an instrument for the assessment of onset and early course of schizophrenia. Schizophrenia Research, 6, 209-223.

Häfner, H., Maurer, J., Löffler, W., et al (1993) The influence of age and sex on the onset and early course of schizophrenia. British Journal of Psychiatry, 162, 80-86.

Harrigan, S. M., McGorry, P. D. \& Krstev, H. (2003)

Does treatment delay in first-episode psychosis really matter? Psychological Medicine, 33, 97-110.

Harris, M. G., Henry, L. P., Harrigan, S. M., et al (2005) The relationship between duration of untreated psychosis and outcome: an eight-year prospective study. Schizophrenia Research, 79, 85-93.

Hegarty, J. D., Baldessarini, R. J., Tohen, M., et al (1994) One hundred years of schizophrenia: a metaanalysis of the outcome literature. American Journal of Psychiatry, 15I, 1409-1416. 
Ho, B. C., Andreasen, N. C., Flaum, M., et al (2000) Untreated initial psychosis: its relation to quality of life and symptom remission in first-episode schizophrenia. American Journal of Psychiatry, I57, 808-815.

Johannessen, J. O., Larsen, T. K., Joa, I., et al (2005) Pathways to care for first-episode psychosis in an early detection healthcare sector. Part of the Scandinavian TIPS study. British Journal of Psychiatry, 187 (suppl. 48), s24-s28.

Johnstone, E. C., Crow, T. J., Johnson, A. L., et al (1986) The Northwick Park Study of first episodes of schizophrenia. I. Presentation of the illness and problems relating to admission. British Journal of Psychiatry, I48, $115-120$.

Larsen, T. K., McGlashan, T. H. \& Moe, L. C. (1996) First-episode schizophrenia: I. Early course parameters. Schizophrenia Bulletin, 22, 24I-256.

Loebel, A. D., Lieberman, J. A., Alvir, J. M., et al (1992) Duration of psychosis and outcome in firstepisode schizophrenia. American Journal of Psychiatry, 149, 1183-1188.

Malla, A. K., Norman, R. M., Manchanda, R., et a (2002) One year outcome in first episode psychosis: influence of DUP and other predictors. Schizophrenia Research, 54, 23I-242.

Malla, A., Norman, R., Scholten, D., et al (2005) community intervention for early identification of first episode psychosis: impact on duration of untreated psychosis (DUP) and patient characteristics. Social Psychiatry and Psychiatric Epidemiology, 40, 337-344.

Marshall, M., Lewis, S., Lockwood, A., et al (2005) Association between duration of untreated psychosis and outcome in cohorts of first-episode patients: a systematic review. Archives of General Psychiatry, 62. 975-983.

McGlashan, T. H. (1988) A selective review of recent North American long-term followup studies of schizophrenia. Schizophrenia Bulletin, 14, 515-542.

McGlashan, T. H. (2006) Is active psychosis neurotoxic? Schizophrenia Bulletin, 32, 609-613.

McGorry, P. D., Yung, A. R., Phillips, L. J., et al (2002) Randomized controlled trial of interventions designed to reduce the risk of progression to first-episode psychosis in a clinical sample with subthreshold symptoms. Archives of General Psychiatry, 59, 921-928.

\section{Melle, I., Larsen, T. K., Haahr, U., et al (2004)}

Reducing the duration of untreated first-episode psychosis: effects on clinical presentation. Archives of General Psychiatry, 61, 143-150.

Moller, P. (2000) First-episode schizophrenia: do grandiosity, disorganization, and acute initial development reduce duration of untreated psychosis? An exploratory naturalistic case study. Comprehensive Psychiatry, 4I, 184-190.

Moller, P. (200I) Duration of untreated psychosis: are we ignoring the mode of initial development? An extensive naturalistic case study of phenomenal continuity in first-episode schizophrenia.

Psychopathology, 34, 8-14.

Morrison, A. P., French, P., Parker, S., et al (2006)

Three-year follow-up of a randomized controlled trial of cognitive therapy for the prevention of psychosis in

SWARAN P. SINGH, MB BS, MD, FRCPsych, DM, Health Sciences Research Institute, University of Warwick, Coventry CV4 7AL, UK. Email: S.P.Singh@warwick.ac.uk

people at ultrahigh risk. Schizophrenia Bulletin. Epub ahead of print.

National Institute for Mental Health in England (2006) UK Early Intervention Community (newsletter 2006). http: / /www.csip.plus.org.uk/RowanDocs/ ElupdateOct2006.pdf

Norman, R. M. \& Malla, A. K. (200I) Duration of untreated psychosis: a critical examination of the concept and its importance. Psychological Medicine, 3I, $381-400$.

Norman, R. M. G., Townsend, L. \& Malla, A .K. (200I) Duration of untreated psychosis and cognitive functioning in first-episode patients. British Journal of Psychiatry, 179, 340-345.

Pantelis, C., Velakoulis, D., McGorry, P. D., et al (2003) Neuroanatomical abnormalities before and after onset of psychosis: a cross-sectional and longitudinal MRI comparison. Lancet, 36I, 28I-288.

Perkins, D., Lieberman, J., Gu, H., et al (2004) Predictors of antipsychotic treatment response in patients with first-episode schizophrenia, schizoaffective and schizophreniform disorders. British Journal of Psychiatry, 185, 18-24.

Perkins, D. O., Gu, H., Boteva, K., et al (2005) Relationship between duration of untreated psychosis and outcome in first-episode schizophrenia: a critical review and meta-analysis. American Journal of Psychiatry, 162, 1785-1804.

Petersen, L., Jeppesen, P., Thorup, A., (2005) A randomised multicentre trial of integrated versus standard treatment for patients with a first episode of psychotic illness. BMI, 33I, 602

Phillips, L. J., Yung, A. R. \& McGorry, P. D. (2000) Identification of young people at risk of psychosis: validation of Personal Assessment and Crisis Evaluation Clinic intake criteria. Australian and New Zealand Journal of Psychiatry, 34 (suppl.) sl64-sl69.

Poulton, R., Caspi, A., Moffitt, T. E., et al (2000) Children's self-reported psychotic symptoms and adult schizophreniform disorder: a 15-year longitudinal study. Archives of General Psychiatry, 57, 1053-1058.

Rabiner, C. J., Wegner, J.T. \& Kane, J. M. (1986) Outcome study of first-episode psychosis. I: Relapse rates after I year. American Journal of Psychiatry, 143 |155-1158.

Riecher-Roessler, A. (2006) The FEPSY (Early Detection of Psychosis) Study - transition rates and predictors of psychosis. Schizophrenia Research, 86 (suppl.) S54.

Scully, P. J., Coakley, G., Kinsella, A., et al (1997) Psychopathology, executive (frontal) and general cognitive impairment in relation to duration of initially untreated versus subsequently treated psychosis in chronic schizophrenia. Psychological Medicine, 27, 13031310 .
Singh, S. P. \& Fisher, H. L. (2000) Early intervention in psychosis: obstacles and opportunities. Advances in Psychiatric Treatment, II, 7I-78.

Singh, S. P., Burns, T., Amin, S., et al (2004) Acute and transient psychotic disorders: precursors, epidemiology, course and outcome. British Journal of Psychiatry, 185, 452-459.

Singh, S. P., Cooper, J. E., Fisher, H. L., et al (2005a) Determining the chronology and components of psychosis onset: the Nottingham Onset Schedule (NOS). Schizophrenia Research, 80, 117-130.

Singh, S. P., Cooper, J. E., Fisher, H. L., et al (2005b) Determining the chronology and components of psychosis onset: The Nottingham Onset Schedule (NOS). Schizophrenia Research, 80, 117-130.

Szymanski, S. R., Cannon, T. D., Gallacher, F., et al (1996) Course of treatment response in first-episode and chronic schizophrenia. American Journal of Psychiatry, I53, 519-525.

Tirupati, N. S., Rangaswamy, T. \& Raman, P. (2004) Duration of untreated psychosis and treatment outcome in schizophrenia patients untreated for many years. Australian and New Zealand Journal of Psychiatry, 38, 339-343.

Vaillant, G. E. (1964) Prospective prediction of schizophrenic remission. Archives of General Psychiatry, II, 509-518.

Verdoux, H., Liraud, F., Bergey, C., et al (200I) Is the association between duration of untreated psychosis and outcome confounded? A two year follow-up study of first-admitted patients. Schizophrenia Research, 49 $231-241$

Warner, R. (2002) Early intervention in schizophrenia: a critique. Epidemiologica e Psichiatria Sociale, II, 248-255.

Wiersma, D., Nienhuis, F. J., Slooff, C. J., et al (1998)

Natural course of schizophrenic disorders: a I5-year followup of a Dutch incidence cohort. Schizophrenia Bulletin, 24, 75-85.

Wyatt, R. J. (199I) Neuroleptics and the natural course of schizophrenia. Schizophrenia Bulletin, 17, 325-35I.

Yung, A. R. \& McGorry, P. D. (1996) The initial prodrome in psychosis: descriptive and qualitative aspects. Australian and New Zealand journal of Psychiatry, 30, 587-599.

Yung, A. R., Phillips, L. J., McGorry, P. D., et al (1998) Prediction of psychosis. A step towards indicated prevention of schizophrenia. British Journal of Psychiatry 172 (suppl. 33), 14-20.

Yung, A. R., Yuen, H. P., McGorry, P. D., et al (2005) Mapping the onset of psychosis: the Comprehensive Assessment of At-Risk Mental States. Australian and New Zealand Journal of Psychiatry, 39, 964-971.

Zipursky, R. B., Lambe, E. K., Kapur, S., et al (1998) Cerebral gray matter volume deficits in first episode psychosis. Archives of General Psychiatry, 55, 540-546. 